\title{
Effect of Amh in Patients with Polycystic Ovarian Syndrome on Pregnancy Rate in Icsi Cycle
}

\author{
Ahmed Mohamed Abd El-Hay ${ }^{1}$, Mohammed Salah Elsayed Elsokkary ${ }^{1}$, Bassem Aly Islam ${ }^{1}$ \\ Department of Obstetrics \& Gynecology, Faculty of Medicine, Ain Shams University
}

*Corresponding author: Ahmed Mohamed Abd El-Hay, Department of Obstetrics \& Gynecology, Faculty of Medicine, Ain Shams University

Received date: May 25, 2021; Accepted date: May 31, 2021; published date: June 08,2021

Citation: Ahmed Mohamed Abd El-Hay, Mohammed Salah Elsayed Elsokkary, Bassem Aly Islam (2021) Effect of Amh in Patients with Polycystic Ovarian Syndrome on Pregnancy Rate in Icsi Cycle. J.Women Health Care and Issues 4(4); DOI:10.31579/2642-9756/068

Copyright: () 2021 Ahmed Mohamed Abd El-Hay, this is an open access article distributed under the Creative Commons Attribution License, which permits unrestricted use, distribution, and reproduction in any medium, provided the original work is properly cited.

\begin{abstract}
:
Background: Surgical site infections (SSIs) pose considerable morbidity and account for up to $20 \%$ of all nosocomial infections in surgical patients
\end{abstract}

Aim of the Work: to determine the efficacy \& safety of irrigation of subcutaneous tissue by Gentamicin for caesarean section Incision in reducing the risk of post-caesarean wound complications among obese women compared with placebo.

Patients and Methods: This prospective randomized clinical trial study was conducted on total 132 obese patients who underwent elective cesarean section at Ain Shams University Maternity hospitals. This study was conducted on obese women undergoing caesarean section at Ain Shams University Maternity Hospital with the following inclusion and exclusion criteria. Patients were distributed randomly into 2 groups using a computer based program: Group (A) $\mathrm{N}$ = 66: CS with Irrigation of subcutaneous tissue by placebo $(200 \mathrm{ml}$ of saline $0.9 \%)$. Group (B) $\mathrm{N}=66$ : CS with irrigation of subcutaneous tissue by Gentamicin solution ( $1 \mathrm{mg} / \mathrm{kg}$ gentamicin in $200 \mathrm{ml}$ of saline $0.9 \%)$.

Results: The results of this study revealed that the rate of SSI was less in gentamycin $(3 \%)(\mathrm{n}=2 / 66)$ than control group $(4.5 \%)(n=3 / 66)$ with no statistical significance between them. Postoperative hospital stay and readmission rate due to SSI for the gentamycin group were also shorter but not statistically different in compared to the control group. Applying local gentamycin antibiotic irrigation during wound closure after cesarean section in obese patients is not recommended. NO role of local gentamycin irrigation in subcutaneous tissue in prevention of wound surgical site infection.

Conclusion: as evident from the current study, in obese women undergoing elective CS, wound irrigation with Gentamicin is not superior to wound irrigation with placebo (saline 0.9 ) regarding efficacy \& safety.

Key words: subcutaneous gentamicin irrigation; wound infection; obesity; cesarean section

\section{Introduction}

Surgical site infections (SSIs) result in prolonged hospitalization and increase the probability of intensive care unit admission and readmission to the hospital with increased mortality [1].

As a result, SSIs represent a substantial financial burden for both the patient and the health service [2]. The SSIs-related actual cost may be even higher than estimated due to underreporting and the financial cost to society from disability payments, loss of tax revenue, and lost productivity [3].

Wound complication, even if not accompanied by an infection, is a significant cause of postoperative morbidity following cesarean delivery. In addition to the increased cost of care, there is the inconvenience of therapy, increased postoperative pain and convalescence, as well as difficulty with activities of daily living [4].
SSIs is divided into incisional SSI and organ/space SSI. Incisional SSI is further divided into superficial and deep incisional SSI. Superficial Incisional Surgical Site Infection involves skin or subcutaneous tissue cellulitis, seroma, hematoma, wound healing disruption, or dehiscence. Deep Incisional Surgical Site Infection involves deep soft tissues such as fascia or muscle within incision. Organ/Space Surgical Site Infection involves any part of the anatomy other than the incision. SSI is associated with a maternal mortality rate of up to $3 \%$ [5].

Obesity is an independent risk factor for post-operative surgical site infection. The risk of post-cesarean surgical site infection has been shown to double for every 5 unit increase in body mass index (BMI) above 30 $\mathrm{kg} / \mathrm{m}$, occurring in about $10 \%$ of obese women undergoing caesarean section despite prophylactic strategies e.g. antibiotics [6]. 
Antibiotic prophylaxis has been a cornerstone in SSI prevention, and there is growing interest in the local delivery of antibiotics. Local delivery can potentially lead to a higher concentration of antibiotics within the target site while minimizing the risk of systemic toxicity [3].

\section{Aim of the Work}

The aim of the study is to determine the efficacy \& safety of irrigation of subcutaneous tissue by Gentamicin for Cesarean Section Incision in reducing the risk of post-cesarean wound complications among obese women compared with placebo.

\section{Patients and Methods}

After ethical committee approval and informed consent from the patients, this prospective randomized clinical trial study was done

\section{Study Period:}

This study will be conducted in the period from October 2020 till the required number of study subjects is recruited (within 6 months ) and all eligible patients finish the work up planned in our study.

\section{Study Methodology: $(\mathbf{N}=132)$}

This study will be conducted on obese women undergoing caesarean section at Ain Shams University Maternity Hospital.

The study will include patients who are consenting to be recruited in the study and fulfilling the inclusion criteria.

After enrolment in the study an informed written consent will be obtained from all participants before recruitment in the study and after explaining the purpose, possible risks and complications eg: postpartum haemorrhage or blood transfusion

The study included patients with ages from (20 - 35years old), BMI between (30_40 kg/m²), elective Cs (primary or repeated CS), single, viable, term pregnancy, expected fetal weight $(2.5-3.5 \mathrm{~kg})$ and $\mathrm{Hb}$ level $>10 \mathrm{gm} \%$.

While patients with medical or obstetric conditions that could put the patient at risk for uterine atony, postpartum hemorrhage or infection such as anemia ( $\mathrm{Hb}$ level $\leq 10 \mathrm{gm} \%)$ and abruptio placenta and Placental site abnormalities eg: Placenta Previa (Placenta accreta, Placenta Increta, Placenta Percreta) were excluded from the study.

\section{Study procedures:}

The patients were distributed randomly into 2 groups using a computer based program:

Group (A) N = 66: CS with Irrigation of subcutaneous tissue by placebo (200 $\mathrm{ml}$ of saline $0.9 \%$ )

Group (B) $\mathbf{N}=$ 66: CS with irrigation of subcutaneous tissue by Gentamicin solution $(1 \mathrm{mg} / \mathrm{kg}$ gentamicin in $200 \mathrm{ml}$ of saline $0.9 \%$ )

All patients were subjected to:

\section{History taking:}

Personal (age, duration of marriage), present (any current medical or surgical diseases and any current medication), past history (history of any medical disorders), obstetric history (including Parity, Gestational age, obstetric complications), Contraception history and Menstrual history.

\section{Clinical examination:}

A-General examination: assessment of the patients general condition (chronic fatigue eg: in anemic patients), body mass index (BMI) measured in $\mathrm{kg} / \mathrm{m}^{2}$, color of complexion eg: pallor in anemic patients, 4) Vital data (pulse, blood pressure, temperature) and cardiac and chest auscultation to exclude contraindications for anesthesia.

B-Abdominal examination: Assessment of fundal level, fetal lie, presentation, liquor volume and previous scar if present.

C-Vaginal examination: to exclude cervical changes, rupture of membranes.

\section{Investigation}

A- Ultrasound examination: 2D ultrasound was carried out transabdominally to assess fetal viability, number, determine gestational age, and exclude any uterine anomalies, fetal anomalies and exact placental location.

B -Baseline laboratory investigations: venous blood sample was withdrawn from all participants to assess: hemoglobin level, total leukocyte count, hematocrit value, platelet count, RH and blood group, viral markers (HBs Ag, HCV Ab) and coagulation profile (PT, PTT, and INR).

All caesarean sections were performed by a senior registrar capable of performing elective cesarean section.

Patients in both groups received intravenous antibiotic (1st generation cephalosporins eg: Cefazolin ${ }^{\circledR} 2 \mathrm{gms}$ ) 30:60 minutes before skin incision to be repeated if the operation lasted for more than 3 hours or blood loss was more than $1000 \mathrm{cc}$. Cephalosporins may be replaced by Ampicillin/Sulbactam in case of Cephalosporins hypersensitivity (ACOG, 2018).

Operative steps: All operations were performed under regional spinal anesthesia, sterilization of urethral meatus and catheterization under aseptic conditions, scrubbing the abdomen was done by using povidone iodine solution $10 \%$, vaginal toilet was done to all patients with povidone iodine solution before the operation, Pfannenstiel incision of the skin was done (Any scar of previous section was removed in both groups) followed by opening of abdominal wall in layers then lower transverse uterine incision and delivery of the baby (without assistance by using forceps) followed by complete delivery of the placenta by controlled cord traction.

Oxytocin (5 IU by slow intravenous injection) was used to encourage contraction of the uterus and to decrease blood loss (RCOG, 2016), the uterus was sutured in 2 layers using vicryl ${ }^{\circledR} 1 / 0$ sutures followed by closure of the rectus sheath, closure of the subcutaneous layer (in case its thickness $>2 \mathrm{~cm}$ ) with interrupted absorbable sutures (vicryl ${ }^{\circledR}$ )

Irrigation of subcutaneous tissue by $200 \mathrm{ml}$ saline $0.9 \%$ IN control group or irrigation by $1 \mathrm{mg} / \mathrm{kg}$

Gentamicin in $200 \mathrm{ml}$ of saline $0.9 \%$ in study Group, + (insertion of subcutaneous drain to be removed after $48 \mathrm{~h}$ )

The skin was sutured by non-absorbable polypropylene suture $0 / 2$ (Mattres suture).

Vaginal toilet was done postoperative

Wound was dressed postoperatively, to be changed after 48 hours. In case it gets wet before 48 hours

It is to be dressed in an aseptic non-touch technique

\section{Post-operative care:}

1) Postoperative patient care was the same for both groups.

2) All patients received Non-Steroidal Anti-Inflammatory drugs in form of (Diclofenac Sodium $®$ ) 75mg IM (one ampule) immediately postoperative then one ampoule 12 hours postoperative (Altman,2015). 
3) Vital signs (pulse, blood pressure, temperature) of the patients were measured four times daily during hospitalization.

4) At 6 h postoperatively, urinary Foley catheters were removed and oral intake with clear fluids was started (ACOG, 2008).

5) A venous blood sample for complete blood count examination was withdrawn after 24 hours postoperative.

6) Regular antipyretic was not used so as not to mask possible postpartum pyrexia.

7) Patients were instructed to inform us if any sign or symptoms of wound sepsis is found

8) Wound should be assessed after 48 hours (before discharge) to exclude septic wound

9) Patients were instructed for postoperative wound care e.g: to always keep wound dressing dry and clean and in case it gets wet it is to be dressed in an aseptic non-touch technique.
10) Patients attended outpatient clinic in El Demerdash Maternity hospital a week after CS. to remove the stitches and to exclude septic wound.

\section{Ethical Considerations:}

The patient's data was anonymous, and patient confidentiality was protected

Study funding: this study didn't receive funding

\section{Statistical analysis:}

Recorded data were analyzed using the statistical package for social sciences, version 20.0 (SPSS Inc., Chicago, Illinois, USA). Quantitative data were expressed as mean \pm standard deviation (SD). Qualitative data were expressed as frequency and percentage. Probability (P-value): $\mathrm{P}$ value $<0.05$ was considered significant.

\section{Results}

Table (1) shows that: No statistically significant difference between study groups. \& control group regarding SSI

\begin{tabular}{|c|c|c|c|c|}
\hline Findings & $\begin{array}{l}\text { Study } \\
(\mathrm{N}=66)\end{array}$ & $\begin{array}{c}\text { Control } \\
(\mathrm{N}=66)\end{array}$ & $P$-value & $\begin{array}{c}\text { Effect size } \\
\text { Relative risk } \\
(95 \% \text { CI })\end{array}$ \\
\hline SSI & $2(3.0 \%)$ & $3(4.5 \%)$ & \multirow{2}{*}{$\S 0.999$} & \multirow{2}{*}{$\begin{array}{c}0.67 \\
(0.12-3.86)\end{array}$} \\
\hline No SSI & $64(97.0 \%)$ & $63(95.5 \%)$ & & \\
\hline
\end{tabular}

Table (1): Surgical site infection (SSI) among the studied groups

Table (2) shows that: Time of occurrence of SSI was statistically non-significant between study groups.

\begin{tabular}{|c|c|c|c|c|}
\hline Findings & $\begin{array}{l}\text { Study } \\
(\mathrm{N}=2)\end{array}$ & $\begin{array}{c}\text { Control } \\
(\mathbf{N}=\mathbf{3})\end{array}$ & P-value & $\begin{array}{c}\text { Effect size } \\
\text { Relative risk } \\
(95 \% \mathrm{CI})\end{array}$ \\
\hline Before discharge from hospital & $0(0.0 \%)$ & $1(33.3 \%)$ & \multirow{2}{*}{$\S 0.999$} & \multirow{2}{*}{ Not applicable } \\
\hline After discharge from hospital & $2(100.0 \%)$ & $2(66.7 \%)$ & & \\
\hline
\end{tabular}

$\S$ Fisher's exact test. CI: Confidence interval. Effect size: Value of study over control

Table (2): Time of occurrence of surgical site infection among the studied groups

Table (3) shows that: No statistically significant difference between the studied groups regarding postoperative hospital stay.

\begin{tabular}{|c|c|c|c|c|}
\hline Measures & $\begin{array}{c}\text { Study } \\
(\mathbf{N}=66)\end{array}$ & $\begin{array}{c}\text { Control } \\
(\mathrm{N}=66)\end{array}$ & ${ }^{\wedge} \mathbf{P}$-value & $\begin{array}{c}\text { Effect size } \\
\text { Mean } \pm \text { SE } \\
95 \% \text { CI }\end{array}$ \\
\hline Mean \pm SD & $1.3 \pm 0.5$ & $1.4 \pm 0.7$ & \multirow{2}{*}{0.302} & $-0.1 \pm 0.1$ \\
\hline Range & $1.0-3.0$ & $1.0-4.0$ & & $-0.3-0.1$ \\
\hline
\end{tabular}

$\wedge$ Independent t-test. CI: Confidence interval. *Significant. Effect size: Value of study over control

Table (3): Postoperative hospital stay (days) among the studied groups

Table (4) shows that: Readmission due to SSI was statistically non-significant among study group.

\begin{tabular}{|c|c|c|c|c|}
\hline Findings & $\begin{array}{l}\text { Study } \\
(\mathrm{N}=2)\end{array}$ & $\begin{array}{c}\text { Control } \\
(\mathbf{N}=\mathbf{3})\end{array}$ & P-value & $\begin{array}{c}\text { Effect size } \\
\text { Relative risk } \\
(95 \% \mathrm{CI})\end{array}$ \\
\hline Present & $0(0.0 \%)$ & $1(1.5 \%)$ & \multirow{2}{*}{$\S 0.999$} & \multirow{2}{*}{ Not applicable } \\
\hline Absent & $66(100.0 \%)$ & $65(98.5 \%)$ & & \\
\hline
\end{tabular}

$\S$ Fisher's exact test. CI: Confidence interval. Effect size: Value of study over control

Table (4): Hospital Readmission due to SSI among the studied groups

Table (5) shows that: No statistically significant difference between the studied groups regarding drug side effects.

\begin{tabular}{|l|c|c|c|c|}
\hline \multicolumn{1}{|c|}{ Findings } & $\begin{array}{c}\text { Study } \\
\mathbf{( N = 6 6 )}\end{array}$ & $\begin{array}{c}\text { Control } \\
(\mathbf{N = 6 6 )}\end{array}$ & $\begin{array}{c}\text { Pffect size } \\
\text { Relative risk } \\
(\mathbf{9 5 \%} \text { CI) }\end{array}$ & $\begin{array}{c}1.50 \\
(0.26-8.69)\end{array}$ \\
\hline GIT upset & $3(4.5 \%)$ & $2(3.0 \%)$ & $\S 0.999$ & \\
\hline
\end{tabular}




\begin{tabular}{|l|c|c|c|c|}
\hline Wound Swelling & $1(1.5 \%)$ & $2(3.0 \%)$ & $\S 0.999$ & $\begin{array}{c}0.50 \\
(0.05-5.38)\end{array}$ \\
\hline Wound Itching, Rash & $2(3.0 \%)$ & $1(1.5 \%)$ & $\S 0.999$ & $(0.19-21.53)$ \\
\hline
\end{tabular}

\#Chi square test. §Fisher's exact test. CI: Confidence interval. Effect size: Value of study over control

Table (5): Side effects of used Drug among the studied groups

\section{Discussion}

Antibiotic prophylaxis has been a cornerstone in SSI prevention, and there is growing interest in the local delivery of antibiotics. Local irrigation can potentially lead to a higher concentration of antibiotics within the target site while minimizing the risk of systemic toxicity [3].

Since obesity and postoperative surgical site infections after cesarean section represent major conflict, Infusion of an antibiotic into the subcutaneous space as a prevention of deep wound infection in morbidly obese patients was highlighted as the main point of interest [7].

The aim of this study was to determine the efficacy \& safety of irrigation of subcutaneous tissue by Gentamicin for caesarean section incision to reduce the risk of post-caesarean wound complications among obese women compared with placebo.

During this study, 173 patients were assessed for eligibility and 132 patients were included in the study. Of all eligible patients, 41 patients were excluded from the study based on the inclusion criteria $(n=34)$ and refusal to participate in the study $(n=7)$.

The remaining 132 were randomized so that 66 were allocated in study and control groups. After then in the study group, one case was excluded due to postpartum haemorrhage and another 2 cases were lost to follow up. While in the control group 2 cases were lost to follow up.

Ultimately, the analysis was done based on the data of 132 patients who approved to participate in the study with age 20-35 years old, BMI between (30_40 kg/m²) with $\mathrm{Hb}$ level $>10 \mathrm{gm} \%$ with singleton, viable and term pregnancy.

The current study revealed that there was no statistically significant difference between the studied groups regarding the patients demographic characteristics (maternal age, BMI, parity and gestational age) (p values $=0.297,0.756,0.538,0.483$ ) respectively.

The results of this study revealed that the rate of SSI was less in gentamicin (3\%) than control group $(4.5 \%)$ with no statistically significant difference between them ( $\mathrm{p}$ value $=0.999$ ).

These results are in agreement with results of previous study done by Shaffer et al. [8] which revealed that wound infection rates were $10.8 \%$ in the study group compared to $10.9 \%$ in the control group which was obviously a non-significant difference [9].

On the contrary, Dineen et al., [10] reported a reduction of nearly 50 per cent in the rate of SSI in the intervention groups explained by high dose of gentamicin ( $2 \mathrm{mg} / \mathrm{kg}$ of gentamicin in $20 \mathrm{~mL}$ of sterile saline) related to the current study and was injected into the subcutaneous tissues instead of being irrigated.

Also, Christou et al. [11] reported a $20 \%$ incidence of wound infection following surgical procedure in control group than gentamicin group.

The results of the current study revealed that the postoperative hospital stay and readmission rate due to SSI for the gentamicin group were also shorter but not statistically different in compared to the control group ( $\mathrm{p}$ value $=0.302,0.999$ ) respectively.
These results are in agreement with results of previous study done by Dineen et al. [10] which revealed that there was no difference in the length of hospital staying or the rate of serious adverse events and the readmission rates in both groups ( $\mathrm{p}$ value $>0.05$ ).

The results of this study revealed that there was no statistically significant difference between the studied groups regarding side effects (GIT upset, wound itching and wound swelling).

These results are in agreement with results of previous study done by Dineen et al. [10] who revealed that no adverse effect reported due to local gentamicin.

The main strength point of this current study is that it is the first to evaluate the efficacy of local wound irrigation with gentamicin in Ain Shams Maternity Hospital as a predictor of decreased wound SSI after Cesarean section in obese patients.

\section{Conclusion}

As evident from the current study, in obese women undergoing elective CS, wound irrigation with Gentamicin is not superior to wound irrigation with placebo (saline 0.9 ) regarding efficacy \& safety.

\section{References}

1. Engemann JJ, Carmeli Y, Cosgrove SE, Fowler VG, Bronstein MZ, Trivette SL, Briggs JP, Sexton DJ and Kaye KS. (2003). Adverse clinical and economic outcomes attributable to methicillin resistance among patients with Staphylococcus aureus surgical site infection. Clinical infectious diseases; 36(5):592-598.

2. Urban JA. (2006). Cost analysis of surgical site infections. Surg Infect.; 7 (suppl 1):19-22.

3. Chang CC, Wang IT, Chen YH and Lin HC (2011). Anesthetic management as a risk factor for post-partum hemorrhage after cesarean deliveries. Am J Obstet Gynecology; 205; 462-467.

4. Orth TA, Gerkovich MM, Heitmann E, Overcash J, Gibbs C and Parrish M. (2016). Cesarean delivery with external negative pressure dressing system: a retrospective cohort study. The Surgery Journal, 2(03), e59-e65.

5. Zuarez-Easton S, Zafran N, Garmi G and Salim R. (2017). Post cesarean wound infection: prevalence, impact, prevention, and management challenges. International journal of women's health; 9, 81-85.

6. Hyldig N, Joergensen JS, Wu C, Bille C, Vinter CA, Sorensen JA and Kruse M. (2019). Cost effectiveness of incisional negative pressure wound therapy compared with standard care after caesarean section in obese women: a trial-based economic evaluation. An International Journal of Obstetrics \& Gynaecology, 126(5), 619-627.

7. Alexander JW and Rahn R. (2004). Prevention of Deep Wound Infection in Morbidly Obese Patients by Infusion of an Antibiotic into the Subcutaneous Space at the Time of Wound Closure. OBES SURG 14: 970-974.

8. Shaffer DA, Benotti PN, Bothe Jr AL, Jenkins RL, Blackburn GL. (1987). A prospective, randomized trial of abdominal wound drainage in gastric bypass surgery. Ann Surg; 206: 134-137.

9. Coletta D, Del Basso C, Giuliani G, Guerra F. (2019). Subcutaneous suction drains do not prevent surgical site infections 
in clean-contaminated abdominal surgery-results of a systematic review and meta-analysis. Langenbecks Arch Surg.; 404(6):663668.

10. Dineen SP, Pham TH, Murray BW, Parker BJ, Hartless K, Anthony T and Huerta S. (2015). Feasibility of subcutaneous gentamicin and pressurized irrigation as adjuvant strategies to reduce surgical site infection in colorectal surgery: results of a pilot study. Am Surg.; 81(6):573-579.

11. Christou NV, Jarand J, Sylvestre JL and McLean AP. (2004). Analysis of the incidence and risk factors for wound infections in open bariatric surgery. Obesity surgery; 14(1):16-22. 